\title{
Gingival Enlargement in Antihypertensive Medication
}

\author{
Pradhan $\mathrm{S}^{1}$ Mishra P' \\ 'Department of Dental surgery, National Academy of Medical Sciences, Bir Hospital, Kathmandu, Nepal
}

\begin{abstract}
Introduction: Drug-induced gingival enlargement is a well documented side effect with the use of phenytoin, cyclosporine and calcium channel blockers. The prevalence of gingival enlargement induced by calcium channel blockers is uncertain. Several studies show conflicting results ranging from $20 \%$ to $83 \%$. This study was conducted to determine the prevalence of gingival enlargement in patients taking antihypertensive medication.
\end{abstract}

Methods: All consecutive patients on antihypertensive agents attending the Dental OPD were studied. The prevalence of drug induced gingival enlargement was determined. The periodontal condition of all subjects were assessed including plaque index and probing depth.

Results: Total $81.2 \%$ of subjects taking antihypertensive were seen to have significant enlargement. Among them $71.1 \%$ were taking calcium channel blocker, $21.5 \%$ were taking ACE Inhibitors, and $7.4 \%$ were taking $\beta$ - blockers.

Conclusions: Patients taking antihypertensive agents are at increased risk for gingival enlargement and inflammation is an important cofactor for the expression of this effect.

Key Words: anti-hypertensive drugs, gingival enlargement

\section{INTRODUCTION}

Drug induced gingival enlargement (DIGE), as a well documented side effect has been reported with systemic use of anti-convulsants, immunosuppressants and calcium channel blockers (CCBs). ${ }^{1-8}$ It was first reported in $1939^{6}$ with chronic usage of phenytoin. CCBs, Angiotensin converting enzyme (ACE) inhibitors and $\beta$-blockers are the most commonly prescribed antihypertensives. It has been reported in patients treated with CCBs like nifedipine, ${ }^{9-13}$ nitrendipine, ${ }^{14}$ nicardipine, ${ }^{15}$ felodipine, ${ }^{16}$ and amlodipine. ${ }^{17,18}$
DIGE presents with similar clinical and microscopic appearance. It begins within 3 months as a firm, nodular enlargement limited to keratinized portions of interdental papilla. Histologically, it is characterized by an increase in connective tissue component. Gingival inflammation also appears to be an important predisposing factor suggesting that the lesion is a consequence of interaction between gingival fibroblasts, cellular and biochemical mediators of inflammation and drug metabolites. The present study aims to determine the prevalence and severity of DIGE in patients taking antihypertensive drugs and their relation with oral hygiene status of the patients.

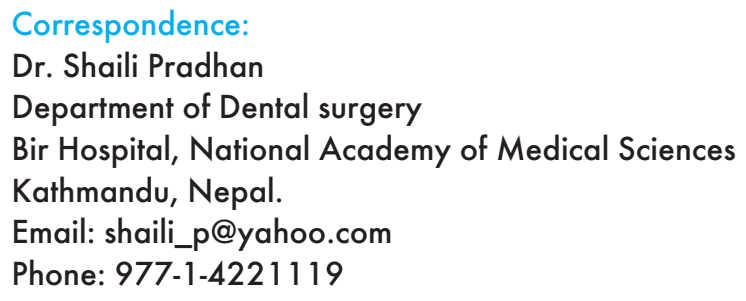




\section{METHODS}

A cross sectional study was carried out among all consecutive patients attending the out patient department (OPD) of dental surgery, Bir Hospital, Nepal Academy of Medical Sciences (NAMS) from July 2008 to December 2008. Ethical approval and patient consent was obtained. Patients presenting with dental problems on antihypertensive agents were included. Gingival enlargement was considered to be present if visible enlargement was present in interdental papilla, marginal gingiva and/or attached gingiva and graded according to the severity into mild (only interdental papilla involved), moderate (marginal gingiva also involved) and severe (attached gingiva also involved). Patients were divided into 4 groups based on the duration of drug consumption viz. group I (0-1 yr), group II (1-5y), group III (5-10 years) and group IV (> 10 years).

Plaque index was considered as described by Quigley and Hein (1962) and divided into good, fair and poor plaque index. ${ }^{18} \mathrm{~A}$ standard periodontal probe (Michigan O probe with William markings) was used to measure the probing depth.

Prevalence rate was determined. It was analysed as per severity; oral hygiene status and duration of drugs consumption using Statistical Package for Social Sciences (SPSS) 13.0 Chi-square test was used to determine statistical significance.

\section{RESULTS}

Total 150 patients taking antihypertensive agents were included. Significant enlargement was seen in $81.2 \%$. The prevalence of gingival enlargement was higher in patients taking CCBs $(71.1 \%)$ followed by ACE inhibitor $(21.5 \%)$ and $\beta$-blockers $(7.4 \%)$. Mild gingival enlargement was seen in $19 \%$, moderate in $71.9 \%$ and severe in $9.1 \%$. Among the CCB users $18.6 \%$ had mild, $74.4 \%$ had moderate and $7.0 \%$ had severe gingival enlargement. Significant difference was not seen in patients using different antihypertensive agents $(P>0.05)$ which possibly shows the effect of poor oral hygiene on gingival enlargement (Table 1). Patients taking antihypertensive agents for 5 to 10 years showed the most severe gingival enlargement (Table 2).

Plaque index was either poor or fair in all patients. None had good plaque index. Among patients with poor oral hygiene, mild gingival enlargement was seen in $10.6 \%$, moderate in $66.4 \%$ and severe in $7.1 \%(P<0.05)$ (Table 3). Poor plaque index was seen among $73.6 \%$ using CCBs, $19.8 \%$ using ACE inhibitors and $6.6 \%$ using $\beta$ blockers (Table 4).

\section{DISCUSSION}

In the study population, prevalence of DIGE was seen in $71.1 \%$ treated with CCBs $21.5 \%$ with ACE Inhibitors group and $7.4 \%$ with $\beta$-blockers. Most patients had moderate severity moderate severity which could be attributed to the poor oral hygiene as well. It is thus difficult to establish whether the high plaque scores observed are the cause or the consequence of the DIGE. Therefore mild enlargement may be a very important factor taken into account for early detection of DIGE in such patients.

Ellis et al in a group of 911 patients treated with CCBs, showed a prevalence lower than in previous studies, with marked differences between the different drugs like nifedipine $(6.3 \%)$, amlodipine $(1.7 \%)$ and diltiazem $(2.2 \%)$ and with higher risk for developing clinically significant gingival enlargement in the patients treated with nifedipine, than in those taking either amlodipine or diltiazem. ${ }^{19}$

Often drug-induced gingival enlargement involves a form of combined gingival enlargement, with the effect of the drug and the inflammatory status and, therefore, it is difficult to determine the contribution of each factor. Some authors have reported a relationship of gingival enlargement with both gingival index and plaque index ${ }^{5,12,20,21}$ indicate that risk factors for DIGE are: drug variables, concomitant medications, periodontal variables, age, gender and genetic factors.

The results of present study suggest that gingival inflammation has a stronger effect than drug treatment itself in patients treated with antihypertensive. This study also reflects the higher tendency of physicians to prescribe calcium channel blockers for patients with hypertension. We must highlight the great number of calcium antagonists, that are being studied and that may have an effect on the gingiva, such as verapamil, ${ }^{22}$ nitrendipine, ${ }^{14}$ felodipine, ${ }^{16}$ oxodipine in rats. ${ }^{23}$

The logical approach in the control of gingival enlargement induced by drugs should be reduction of the dose of the drug or substitution of the drug. Reduction in gingival enlargement has been reported where a different calcium channel blocker, such as Verapmil has been substituted for nifedipine, ${ }^{9}$ but more usually where substitution is made by a structurally different antihypertensive drug, such as the angiostensinconverting enzyme inhibitor, enalapril, ${ }^{24}$ the $\beta$-blocking drug, atenolol, ${ }^{25-27}$ or thiazide diuretics. ${ }^{17,28}$ Change in medication should only be considered for those patients where the new medication can offer some advantage for control of their hypertension, which present with clinically significant enlargement and are at high risk from either corrective surgery or recurrence after gingivectomy. ${ }^{29}$ Reduction in the size of the gingival enlargement has been reported within a week of drug withdrawal, ${ }^{30}$ and may lead to full resolution. 
Pradhan et al. Gingival Enlargement in Antihypertensive Medication

Table 1. Severity of gingival enlargement in patients taking antihypertensive

\begin{tabular}{lccc}
\hline Drugs & \multicolumn{3}{c}{ Severity (\%) } \\
& Mild & Moderate & Severe \\
\hline ACE inhibitors & 11.5 & 73.1 & 15.4 \\
B-blocker & 44.4 & 44.4 & 11.1 \\
Calcium channel blocker & 18.6 & 74.4 & 7.0 \\
\hline
\end{tabular}

Table 2. Relation between duration of drug consumption and severity

\begin{tabular}{llcc}
\hline Duration of drug consumption (in years) & Mild & Severity (\%) & Moderate \\
\hline Group I (0-1) & 14.0 & 53.5 & 9.3 \\
\hline Group II (1-5) & 15.5 & 59.7 & 6.5 \\
Group III (5-10) & 21.4 & 60.7 & 7.1 \\
Group IV (>10) & 18.8 & 56.3 & 6.3 \\
\hline
\end{tabular}

Table 3. Relation between plaque index and severity

\begin{tabular}{lccc}
\hline Plaque index & \multicolumn{2}{c}{ Severity (\%) } \\
& Mild & Moderate & Severe \\
\hline Good & 0 & 0 & 0 \\
Fair & 33.3 & 30.6 & 8.3 \\
Poor & 10.6 & 66.4 & 7.1 \\
\hline
\end{tabular}

Table 4. Relation between plaque index and drugs used

\begin{tabular}{lccc}
\hline Plaque index & ACE Inhibitors & $\boldsymbol{\beta}$-blockers & Calcium channel blocker \\
\hline Good & 0 & 0 & 0 \\
Fair & 20.9 & 14.0 & 65.1 \\
Poor & 19.8 & 6.6 & 73.6 \\
\hline
\end{tabular}

Prevention and treatment includes meticulous plaque control and frequent professional debridement. ${ }^{31}$ Furthermore, resective gingival procedures may be needed to improve function, aesthetics and access for home care. The periodontist is restricted in controlling gingival inflammation, correcting gingival contour and treating any pre-existing periodontal disease. Ideally, all patients about to be medicated with cyclosporine, phenytoin or a calcium channel blocker, should go through a full periodontal assessment and any disease present treated appropriately. Clinicians should be aware of the prevalence and risk of gingival enlargement induced by calcium channel blockers and other antihypertensive in order to implement preventive practices as well as to establish an early diagnosis of this condition.

In Nepal very few studies has been carried out till date to our knowledge and this study could significantly contribute in dealing patients with antihypertensive drugs and create awareness among treating physicians. However, in-depth study with larger sample size to determine the actual prevalence of gingival enlargement with different types of calcium channel blockers, ACE Inhibitors and $\beta$-blockers is required.

\section{CONCLUSIONS}

Patients on CCBs had a higher prevalence of DIGE. DIGE was also seen in patients taking antihypertensive agents like ACE inhibitors and $\beta$-blockers. However, poor oral hygiene could also have contributed to develop gingival enlargement in such patients.

\section{ACKNOWLEDGEMENTS}

This work was supported by the dental surgeons working in the Department of Dental Surgery, Bir Hospital, NAMS. 


\section{REFERENCES}

1. Angelopoulos AP. Diphenylhydantoin gingival hyperplasia. A clinicopathological review. 1. Incidence, clinical features and histopathology. Dent J. 1975 Feb;41(2):103-6.

2. Seymour RA, Jacobs DJ. Cyclosporin and the gingival tissues. J Clin Periodontol. 1992 Jan;19(1):1-11.

3. Rateitschak-Plüss EM, Hefti A, Lörtscher R, Thiel G. Initial observation that cyclosporin-A induces gingival enlargement in man. J Clin Periodontol 1983;10(3):237-46.

4. Calne RY, Rolles K, White DJ, et al. Cyclosporine A in clinical organ grafting. Transplant Proc. 1981;13:349-58.

5. Seymour RA. Calcium channel blockers and gingival overgrowth. Br Dent J. 1991;170:376.

6. Kimball OP. The treatment of epilepsy with sodium diphenyl hydantoinate. J Am Med Assoc. 1939;112:1244-5

7. Brunet L, Miranda J, Farré M, Berini L, Mendieta C. Gingival enlargementinduced by drugs. DrugSaf.1996Sep;15(3):219-31.

8. Dukes MG, Aronson JK. Myler's Side Effects of Drugs: An Encyclopedia of Adverse Reactions and Interactions. 40th ed. New York: Elsevier; 2000.

9. Lederman D, Lumerman H, Reuben S, Freedman PD. Gingival hyperplasia associated with nifedipine therapy. Report of a case. Oral Surg Oral Med Oral Pathol. 1984 Jun;57(6):620-2.

10. Ramon Y, Behar S, Kishon Y, Engelberg IS. Gingival hyperplasia caused by nifedipine--a preliminary report. Int J Cardiol. 1984 Feb;5(2):195-206.

11. Lucas RM, Howell LP, Wall BA. Nifedipine-induced gingival hyperplasia. A histochemical and ultrastructural study.J Periodontol. 1985 Apr;56(4):211-5.

12. Bullon P, Machuca G, Martinez-Sahuquillo A, Rios JV, Rojas J, Lacalle JR. Clinical assessment of gingival hyperplasia in patients treated with nifedipine. J Clin Periodontol. 1994 Apr;21(4):256-9.

13. Miranda J, Brunet L, Roset P, Berini L, Farré M, Mendieta C. Prevalence and risk of gingival enlargement in patients treated with nifedipine. J Periodontol. 2001 May;72(5):605-11.

14. Brown RS, Sein P, Corio R, Bottomley WK. Nitrendipineinduced gingival hyperplasia. First case report. Oral Surg Oral Med Oral Pathol. 1990 Nov;70(5):593-6.

15. Nagano S, Ogawa T, Fukuyama S. Influence of nicardipine hydrochlorhide on hypotensive effect and insulin secretion in a patient of hypertensive diabetic mellitus. Japan Pharmacol Therapeut. 1985;19:5309-13.

16. Lombardi T, Fiore-Donno G, Belser U, Di Felice R. Felodipineinduced gingival hyperplasia: a clinical and histologic study. J Oral Pathol Med. 1991 Feb;20(2):89-92.
17. Seymour RA, Ellis JS, Thomason JM, Monkman S, Idle JR. Amlodipine-induced gingival overgrowth. J Clin Periodontol. 1994 Apr;21(4):281-3.

18. Quigley GA, Hein JW. Comparative classifying efficiency of normal and power brushing. J Am Dent Assoc. 1962;65:26-9.

19. Ellis JS, Seymour RA, Steele JG, Robertson P, Butler TJ, Thomason JM. Prevalence of gingival overgrowth induced by calcium channel blockers: a community-based study. J Periodontol. 1999 Jan;70(1):63-7.

20. Nery EB, Edson RG, Lee KK, Pruthi VK, Watson J. Prevalence of nifedipine-induced gingival hyperplasia. J Periodontol. 1995 Jul;66(7):572-8.

21. Seymour RA, Ellis JS, Thomason JM. Risk factors for druginduced gingival overgrowth. J Clin Periodontol. 2000 Apr;27(4):217-23.

22. Pernu HE, Oikarinen K, Hietanen J, Knuuttila M. Verapamilinduced gingival overgrowth: a clinical, histologic, and biochemic approach. J Oral Pathol Med. 1989 Aug;18(7):422-5.

23. Nyska A, Waner T, Pirak M, Galiano A, Zlotogorski A. Gingival hyperplasia in rats induced by oxodipine--a calcium channel blocker. J Periodontal Res. 1990 Mar;25(2):65-8.

24. Puolijoki H, Siitonen L, Saha H, Suojanen I. Gingival hyperplasia caused by nifedipine. Proc Finn Dent Soc. 1988;84(5-6):311-4

25. Mohapatra BN, Kar BC, Das P. Nifedipine-induced gum hyperplasia. J Assoc Physicians India. 1991 Jun;39(6):506.

26. Bhatia RS. Nifedipine induced reversible gingival hyperplasia. J Assoc Physicians India. 1992 Jul;40(7):486.

27. James JA, Linden GJ. Nifedipine induced gingival hyperplasia. Dental Update. 1992;19:440-1.

28. Nishikawa S, Tada H, Hamasaki A, Kasahara S, Kido J, Nagata T, et al. Nifedipine induced gingival hyperplasia : a clinical and in vitro study. J Periodontol. 1991;62:30-5.

29. Mavrogiannis M, Ellis JS, Thomason JM, Seymour RA. The management of drug-induced gingival overgrowth. J Clin Periodontol. 2006;33:434-9.

30. Raman PG, Mishra VN, Singh D. Nifedipine induced gingival hyperplasia. J Assoc Physicians India. 1988;36:231-3.

31. Seymour RA, Smith DG. The effect of plaque control programme on the incidence and severity of cyclosporineinduced gingival changes. J Clin Periodontol. 1991;18:107-10. 